\title{
ASSESSMENT OF EMOTIONAL STRESS AND HYPERACTIVITY IN CHILDREN OF PRESCHOOL AND EARLY SCHOOL AGE
}

\section{Summary}

\section{Introduction}

Nowadays, one can observe a developing problem: a rising number of children who are slow to succeed in learning and have difficulties in mastering the school program.

\section{Aim of the Study}

The aim of the paper is to assess the level of hyperactivity in children of preschool and early school age, to analyse factors promoting the formation of hyperactivity during pregnancy and early child development as well as to evaluate reactions of children to emotional stress.

\section{Materials and Methods}

There were 46 5-9 years old children observed under the current research. Parents of hyperactive children were given a questionnaire to be filled out: Connerse test in order to find the factors interfering with the development of the child during the mother's pregnancy and the early period of development of the child. In order to obtain the psychophysiological characteristics of the children and to assess the level of their emotional stress, photoplethysmograms (PPG) of children were taken.

\section{Results}

The results of the reasearch show that rather many hyperactive children experience untoward conditions in their early childhood. They may cause disturbances in the development of the nervous system and result in hyperactive behaviour.

\section{Conclusions}

Hyperactive children have more explicit photophlethismogram data fluctuations in comparison with the control group of children, and they evidence a higher emotional stress level during probation procedures. The older group of children (7-9 years old) succeed more in regulating their emotional state in comparison with the younger group of children.

Key words: hyperactive children, photoplethysmogram, peripheral blood flow, emotional stress.

\section{Introduction}

Lately, one can observe that the number of children facing learning problems and having difficulties in mastering the material presented in their school syllabuses has rapidly risen both in Latvia and elsewhere in the world. About one third of all children are easy to exhaust, they often fall ill, suffer from insomnia, have a tendency to worry. About $15 \%$ of the children have trouble with mastering the learning material at school. They have unacceptable behaviour and experience problems in building relationships (Lasmane, 2005). Problems at school and negative emotions can result in serious consequences in the development of their personality. Children show such undesirable problems as emotional imbalance, low self-esteem, inability to comply their behaviour with the overall social norms (Ranka et al., 1996). 
One of the most characteristic disturbances in the children's development is hyperacticity and attention deficit.

\section{Aim of the Study}

The aim of the study was to assess the level of hyperactivity in preschool and early school age children, to analyse the factors contributing to the development of hyperactivity during mother's pregnancy and early development of the child as well as to assess the reaction of children to the emotional stress.

\section{Materials and methods}

Due to various disturbances hyperactive children experience serious problems at school. The most typical are as follows: trouble understanding questions and aswering them, insuffiecient skills in planning and organising learning process, difficulty to sustain the level of activity for performing the tasks, inability to focus attention, problems with overcoming failures. These problems frequently lead to bad school results, influence ability to express oneself, impact memory, development of motion skills, behaviour (Roge, Mēlere, 2003). Teachers and parents cannot manage the behaviour of hyperactive children as the latter have developed dislike for school. Hyperactive children become a risk group of antisocial behaviour (Špalleka, 2003). The ways hyperactivity is expressed change throughout the lifetime. Preschool and early school age children as well as teenagers show different peculiarities of hyperactive behaviour according to the overall development of the organism in ontogenesis when the functions of psychic processes gradually perfect themselves thus altering the expression of the behavioural disorders (Zīrina, 2005).

In their early childhood, many children undergo tention and emotional stress at school. Enduring tention, especially if it is accompanied by the development of negative emotions, can leave a negative impact the health of a child. In cases when there is no adaptation for a long time the well-being and health of the person is endangered. If a child is physically weakened or has limited psychological resources, the stressor can lead to dangerous physical illnesses or psyhical disorders. The beginning of the new academic year takes the first place among the various stressors that preschool and primary school students face at schools. The most critical periods when the tension considerably increases and can influence the child's ability to perform his daily tasks are: the period when child starts attending school, transition from primary to lower secondary school and transition from lower secondary school to upper secondary school. These are periods of crises as the lead to significant changes in both child's school life and his personality (Lasmane, 2005).

Inimic pregnancy, various factors hindering the development of a child's development as well as mental experiences and emotional stress during the first years of life can severely influence child's health. Some disorders, for instance, paroxysmal states, hyperkinesis can be diagnosed very early, whereas disorders in cognitive processes, low intellectual abilities, bad memory, inability to focus attention - only much later. Usually it happens when a child experiences problems in his kindergarten group or cannot cope with tasks given to him at school. If disorders in the nervous system are discovered early on, in most cases it is possible to improve the inadequate behaviour and raise the child's cognitive abilities. Research proves that one of the most significant factors helping to ensure the stability of the person's behaviour under various circumstances is a high level of development of self-regulatory systems of the person's psychophysiological state. The development of self-regulatory systems depend on the specific character of the child's perception and his individual reaction stereotypes that form in early childhood (Moore, 2000). If stable selfregulatory mechanisms do not form during this period and age, the result is behavioural disorders and inability to adapt to school life. That is why children's health problems should be given due 
attention since the earliest developemental periods.

To diagnose a child's funcional state various methods can be used. Electrophysiological examination methods are considered to be the most objective and informative ones. With the help of these methods one can examine the disorders in the functions of various body systems, self-regulatory abilities of the organism, the level of the emotional stress and other parametres. There have been many and manifold electrophysiological methods worked out. They are based on examining the state of the blood circulation system. An informative method clearly showing the specific reaction characteristics of the system of heart blood vessels is called photoplethysmogram (Gerhard-Herman et al, 2006). It is an optic method helping to register the peripheral bloodflow (Foo, Wilson, 2006). The connection between the function of the heart and emotions is well known. The heart mostly reacts to such emotions as anger, hatred and fear (Ancāne, 2004). Thus, methods for examining blood circulation system can provide us with information not only about the specific character of how the blood circulation system functions but also about such parametres as person's functional condition, level of emotional stress, etc. The development of efficient diagnostic methods for examining children's functional conditions and their application will improve the health of the new generation.

There were 46 5-9 years old children observed under the current research. Parents and psychologists had noticed that some of the children show signs of hyperactive behaviour. These children experienced difficulties in fitting into the group, inappropriate behaviour could be observed. To understand the character of children's hyperactivity all parents filled out a questionnaire and did Connerse's test. Children were divided into four groups: a group of young children (from 5 to 7 years old) with hyperactive behaviour, a control group of young children (from 5 to 7 years old), a group of older children (from 7 to 9 years old) with hyperactive behaviour and a control group of older children (from 7 to 9 years old). Children who had reached the age of seven were put into the group of older children.

The questionnaire of Connerse's test has been made so that parents can analyse 10 features of the child (motion activity, excitability, interference into other children's activities, frequent and fast change of the attention focus, fidgeting, inattention and inability to focus attention, impatience and quick disappointment, fast and radical changes of the mood, expressions of rage and unpredictable, furious behaviour) and assess their level of expression: no sign of expression (0), low expression (1), relatively high expression (2) and extremely high expression (3). The total sum of the points show how explicit and high the level of hyperactivity is.

A questionnaire was given to the parents of the hyperactive children in order to find out the factors influencing the development of the child during pregnancy and early childhood.

In order to register the children's psycho physiological specifics and assess the level of their emotional stress, photoplethysmograms (PPG) for all children were made chracterising the peripheral blood flow. PPGs were registred with the help of plygraph "Reakor" (year 2005).

The pulsation amplitude in the photoplethysmograms directly reflect the tone of the resistent arteries and blood sypply in the place where the registerring electrode has been placed. The changes in the PPG scope of amplitude are very considerable - the scope can change even as many as several times. The scope is greatly influenced by the stress related factors. This can be used to check the stress resistance of the respondent (Yashima et al, 2005). When the tone of the arterioles increase, teh scope of PPG decreases. The scope of PPG increases when the blood vessels in hands distend. That is a decrease in the overall peripheral resistence and thus an expression of the maximum decrease in blood pressure.

When resgisterring the photoplethysmogram, the adapter is adjusted on the third phalanx 
of the middle finger on the left arm. During the regsitration of PPG the patient is in a relaxed and passive position. As a stress model we used unexpected, unpleasant noises (for example, the sound of a breaking glass, noise that is made by dragging a piece of metal along glass, siren, the sound of breaks or a crying child). The registration of PPF consisted of several phases. At first, the patient was instructed to relax. Then the intitial background of PPG was registerred. During this period the patient was shown video recordings with nature landscapes and relaxing pieces of music were played. It is necessary to succeed in relatively stabilising the indicators to be registerred. Afterwards, the pantient was informed that $\mathrm{s} /$ he will hear various accustic sounds. Then the sound stress test followed. While having some calm music in the background, sudden unpleasant noises were played. Then the person was told that the relaxation period will follow. The closing background was registerred. The patient was again shown nature landscapes with relaxing music in the background.

\section{Results}

Figure 1 shows the results of Connerse's test for all groups of children (see Figure 1). The childrening forming the control group have not got a high sum of the points (it ranges from 3 to 10; in the younger group the number is 6.2 whereas in the older group the number is 6.5). It proves that these children do not have any signes of hyperactivity and they can be safely considered to be a control group. The sum of the points gathered by hyperactive children according to the Connerse's test ranged from 15 to 24 points. The average sum in the younger group was 17.1 points whereas in the older group - 15.9 indicating a hyperactive behaviour.

Figure 1. The resykts of the Connerse's test for the two groups of children (the total sum).

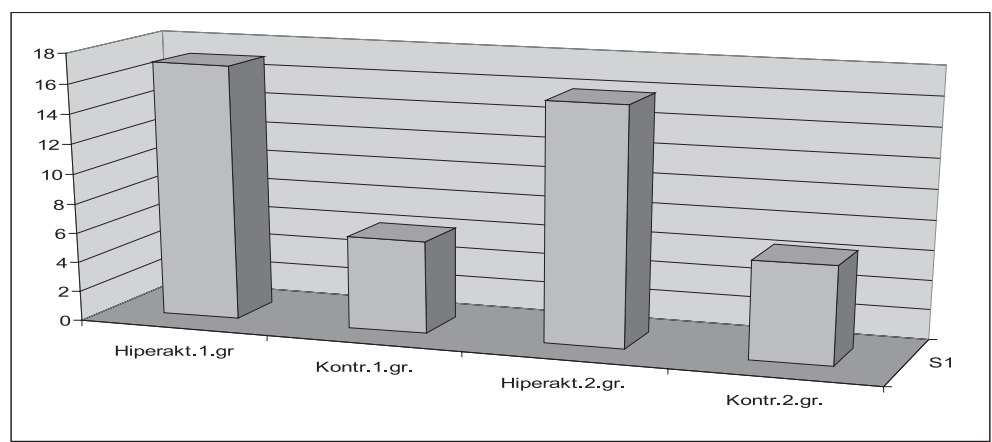

Children in Hyperactive Group 1 - the younger children (aged 5-7) with a hyperactive behaviour. Control Group 1 children in Control Group 1 (aged 5-7 years). Children in Hyperactive Group 2 - the younger children (aged 7-9) with a hyperactive behaviour. Control Group 2 - children in Control Group 1 (aged 7-9 years).

Figure 2 shows the results of the analysis of the factors influcening the development of hyperactive children during the mother's pregnancy and early childhood (see Figure 2). More than a half of the fathers of the hyperactive children had used alcohol before or during the mother's getting pregnant. In several cases the mother has been smoking or drikning during the preganancy. More than one half of the mothers had used medicine during preganancy. Obviously, use of harful substances right before woman's becoming pregant or during pregancy is one of the risk factors that may lead to the child's developmental disorders and hyperactive behaviour. 
Figure 2. The analysis of factors leading to the disorders in child's development for hyperactive children during mothers' pregancy and early childhood.

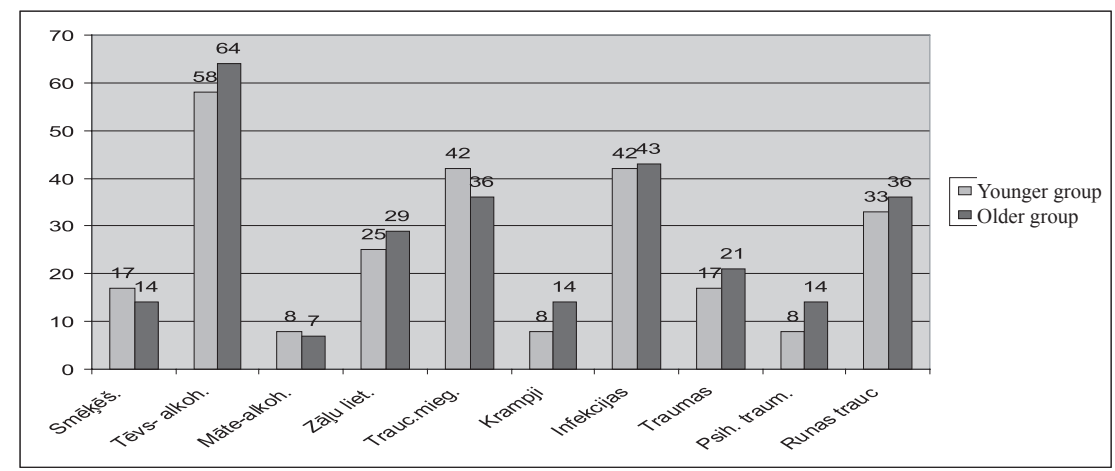

"Smoking” - mother smoking during pregnancy; „Father - alcohol” - father has used alcohol before or during pregnancy; „Use of medicine" - mother has used medicine during pregnancy; „Disorders of sleep” - children have problems with sleeping regime during early childhood; „Cramps” - children have cramps during early childhood; „Infections” - children often catch cold and various infections during early childhood; „Traumas” - children have had a number of traumas during early childhood; „Psychological traumas” - during early childhood the child has had psychological traumas; „Speech disorders” - a child has speech disorders or cannot pronounce certain letters.

Comparatively many of the hyperactive children ( $42 \%$ in the younger group of children aged from 5-7 years and 36\% in the group of older children aged from 7-9 years) have had problems with their sleeping regime during early childhood. $42 \%$ of the hyperactive children in the younger group and $43 \%$ of the children in the older group have had frequent colds and infection deseases during their early childhood. Par of the hyperactive children had experienced physical or phychical traumas during their early childhood. $33 \%$ of the hyperactive children in the younger group and $36 \%$ of the children in the older group had speech disorders or could not correctly pronounce some letters. The results of the research show that part of the hyperactive children during their early childhood have been subjected to unfavourable factors influencing their development. It is highly important that the child should have an orderly sleeping regime, should not have any traumas and infection deseases to have a succesfull and full psychomotirc development. An orderly sleeping regime encourages a wholesome psysical and psychical developemnt of the growing organism. An exceeding excitement of the nervous system can lead to disorders and hyperactive behaviour. When a child catches cold, gets an infectious desease or experiences a trauma, s/he needs to be given extra attention and care as all of these factors can negatively impact further development and lead to attention disorders.

The indicators of the photoplethysmograms in the younger group (children aged from 57) are shown in Figures 3-7: In Figure 3 individual indicators of the children with hyperactive behaviour can be seen, whereas in Figure 7 - the average indicators of the children from control group.

The results of the research show that the children in the younger group with hyperactive behaviour have only two types of blood supply reaction: the first type of reaction is characterised with a rapidly increasing peripheral blood supply; the second one is characterised by a considerably decrease peripheral blood supply in comparison with the control group of children. The first type of reaction was registerred in $74 \%$ of hyperactive children, whereas the second one: in $25 \%$ of hyperactive children. The first type of reaction proves the decrease of the tone in blood vessels and 
a considerably increase in blood supply which is obviously a way of expressing emotional stress. The second type of reaction shows a considerable increase in blood vessel tone which hinders the peripheral blood supply and probably can also be considered a peculiar way of expressing emotional stress. Children with hyperactive behaviour have very unsteady PPG indicators and they have a react very sharply on the test procedure.

Overall, children from the younger group with hyperactive behaviour have their blood supply increasing when the instructions were given to them in comparison with the background; it increases even more during the stress test and remains high during the closing phase exceeding the indicators registerred during the period when the instructions were given. Such a dynamics of PPG indicators prove that the children of the younger group perceive the test procedure (including both the background, instructions, as well as hearing and sight irritants) as a stressful even and they are comparatively unable to regulate the level of their emotional stress. The children from the younger group also perceive the entire procedure as a stressful event, however the changes in the indicators of their peripheral blood supply are not so radical as those of the children with hyperactive behaviour.

Figure 3. Individual indicators (in conditioned units) of the changes in blood supply for children in the younger group (aged 5-7) with hyperactive behaviour during the course of PPG registration.

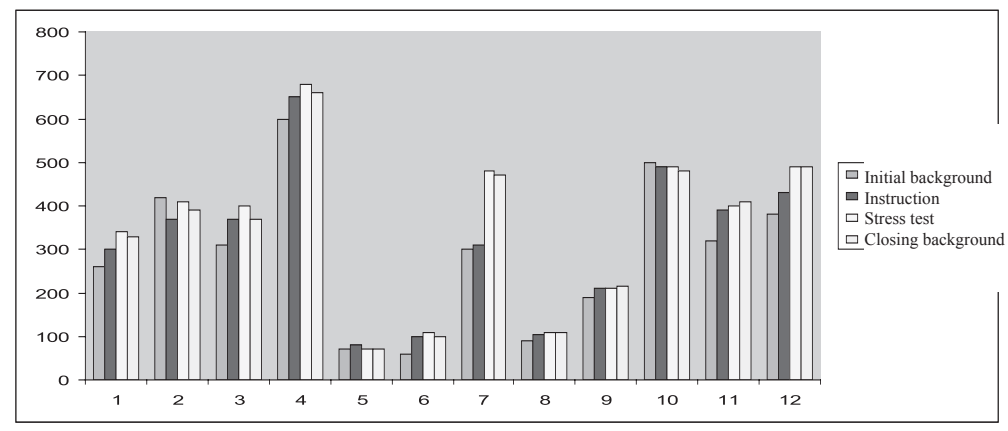

Persons $1-12$ to be tested

Figure 4. Individual indicators (in conditioned units) of the changes in blood supply for children in the younger group (aged 5-7) during the course of PPG registration.

A.

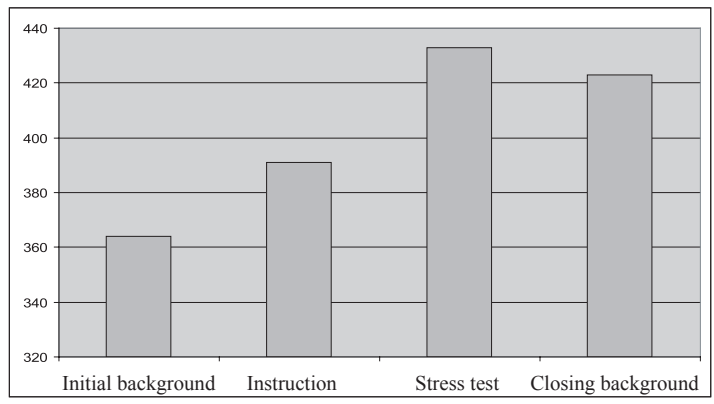

B.

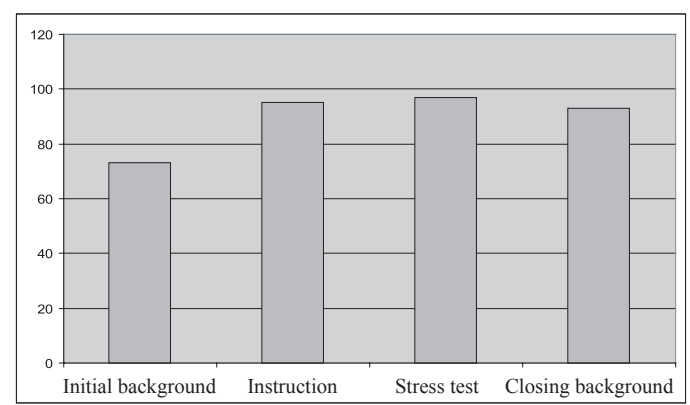

A - average indicators of the children with the first type of reaction and increased blood supply. $\mathrm{B}$ - average indicators of the children with the first type of reaction and decreased blood supply. 
Figure 5. Individual indicators (in conditioned units) of the changes in blood supply for children in the younger group (aged 5-7) with hyperactive behaviour during the course of PPG registration.

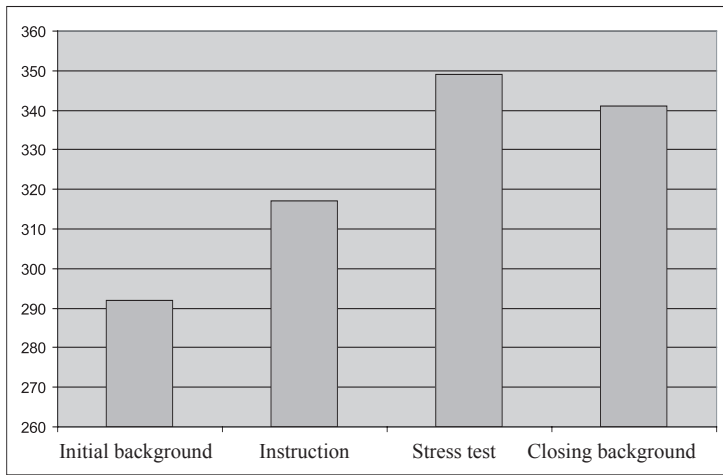

Figure 6. Individual indicators (in conditioned units) of the changes in blood supply for children in the younger control

group (aged 5-7) during the course of PPG registration 1.-10. Persons 1-10 to be tested.

Figure 7. Individual indicators (in conditioned units) of the changes in blood supply for children in the younger control group (aged 5-7) during the course of PPG registration.
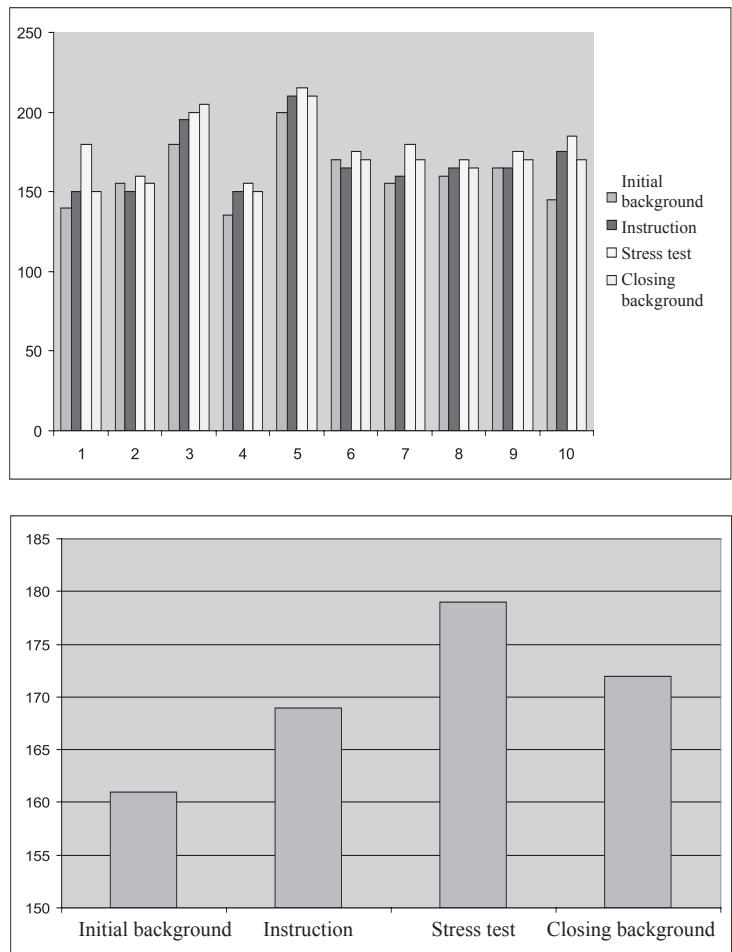

The indicators of the photoplethysmograms in the older group (children aged from 7-9) are shown in Figures 8-7: In Figure 8 individual indicators of the children with hyperactive behaviour can be seen, in Figures 9 and 10 - average indicators of children with hyperactive behaviour, whereas in Figure 11 - the average indicators of the children from control group, and in Figure 12 - average indicators in the control group.

The results of the research show that the children in the older group with hyperactive behaviour have two types of blood supply reaction: just as in the younger group, the first type of reaction is characterised by a rapidly increasing peripheral blood supply; the second one is characterised by a considerable decrease in peripheral blood supply in comparison with the control group of children. The first type of reaction was registerred in $71.4 \%$ of hyperactive children, whereas the second one: in $28.6 \%$ of hyperactive children.

Overall, children from the older group with hyperactive behaviour have their blood supply 
increasing when the instructions were given to them in comparison with the background; it does not increase during the stress test and decreses during the closing phase. Such changes in the dymanics of PPG indicators prove that the children from the older group can control their emoational conditions much better than those in the group of younger children. The indicators of peripheral blood supply for the children in control group in comparison with hyperactive children are less unstable, and they are better at controlling their emotional condition. Even though these children do react on the stressful sounds proved by the fact that during the stressful moments the indicators of the blood supply are higher than during the closing background, the children of the older group also see the entire procedure as a stressful event which they are still able to control better than the children of the younger group.

Figure 8. Individual indicators (in conditioned units) of the changes in blood supply for children in the older group (aged 7-9) during the course of PPG registration

Persons $1-14$ to be tested

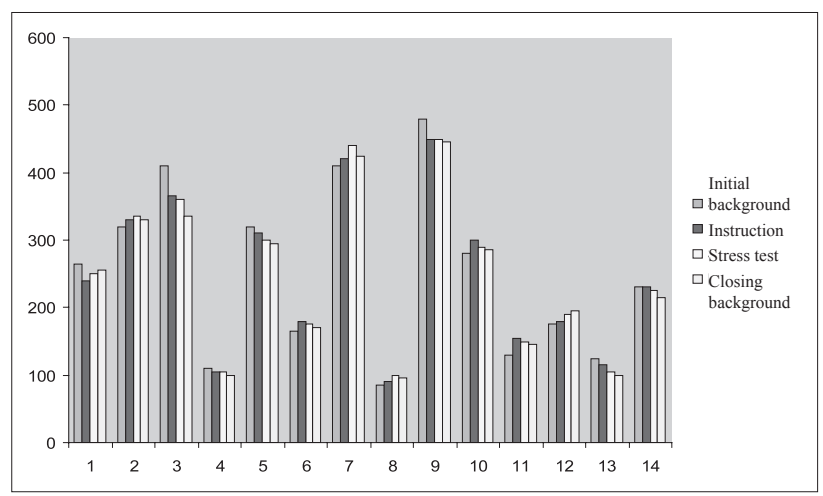

Figure 9. Individual indicators (in conditioned units) of the changes in blood supply for children in the older group (aged 7-9) during the course of PPG registration

A.

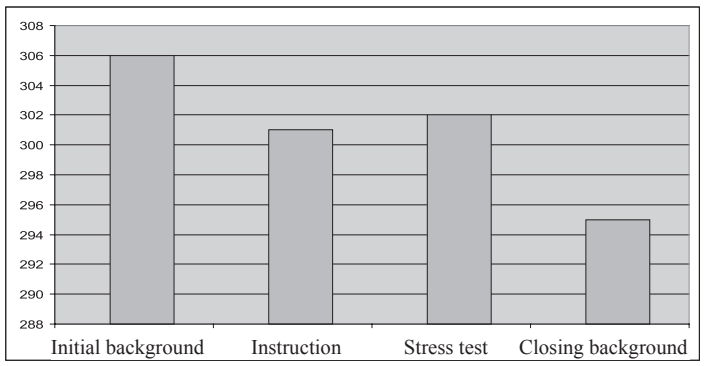

B.

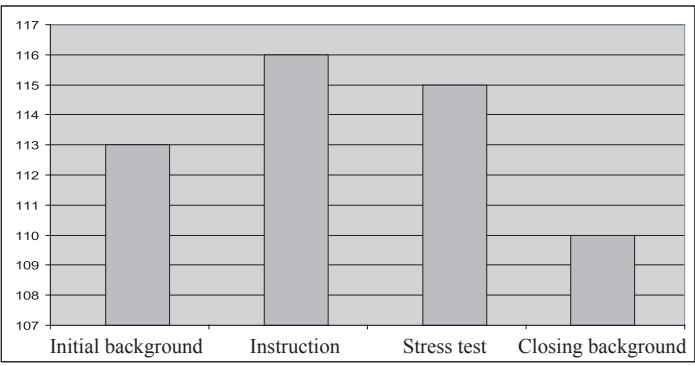

A - average indicators of the children with the first type of reaction and increased blood supply. $\mathrm{B}$ - average indicators of the children with the first type of reaction and decreased blood supply.

Figure 10. Individual indicators (in conditioned units) of the changes in blood supply for children in the older group (aged 7-9) with hyperactive behaviour during the course of PPG registration

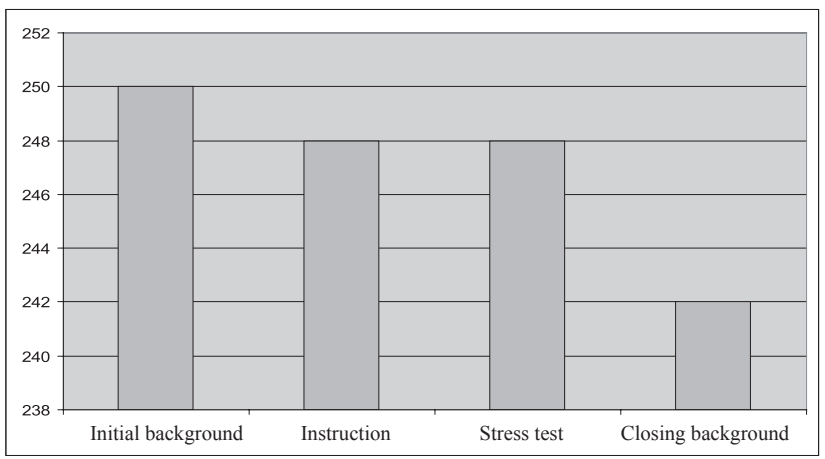


Figure 11. Individual indicators (in conditioned units) of the changes in blood supply for children in the older control group (aged 7-9) during the course of PPG registration

Persons $1-10$ to be tested

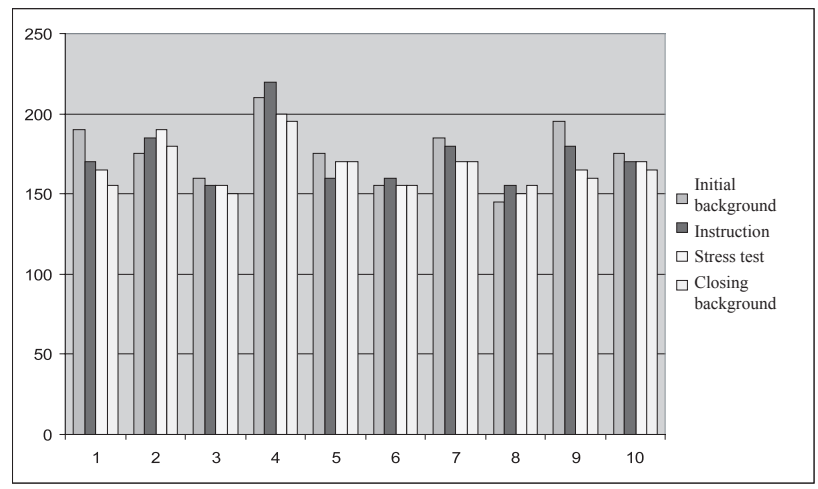

Figure 12. Individual indicators (in conditioned units) of the changes in blood supply for children in the older control group (aged 7-9) during the course of PPG registration

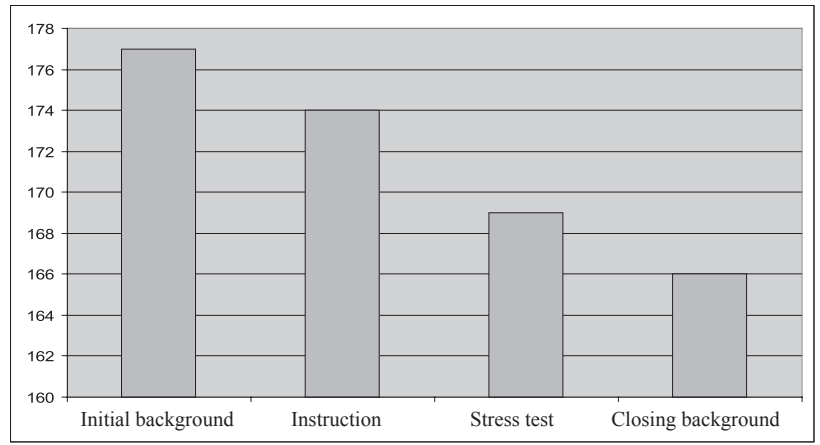

\section{Conclusions}

The development of a child's hyperactvity can be encourage by factors that influence the fetus during the pregnancy and a child during his early childhood: parents' use of alcohol or other harful substances, disorders of sleep, infection deseases, physical and psychologal traumas.

1. Children with hyperactive behaviour have two types of blood supply reaction in cases of emotional stress: the first type of reaction is characterised by a rapidly increasing peripheral blood supply; the second one is characterised by a considerable decrease in peripheral blood supply.

2. The children in the younger group (aged 5-7) perceive the entire testing procedure as a stressful event and they are bad at managing their emotional condition. Hyperactive children have greater changes in photoplethysmogram indicators in comparison with the children from the control group thus proving that they undergo a higher level of stress during the test procedure.

3. The children from the older group (aged 7-9) in comparison with the children in the younger group are better at managing their emotional condition. Hyperactive children in comparison with the children in the control group have more unstable indicators of the peripheral blood suppply which proves that they experience a higher level of stress and it is harder for them to manage their emotional condition.

4. The indicators of photoplethysmograms can be used as a diagnostic method to assess the child's psycho physiological condition and the level of emotional stress. 


\section{REFERENCES}

1. Ancāne G (2004) Sirds asinsvadu sistēmas un elpošanas sistēmas psihosomatiska. Psihologijas pasaule (6), 34.-39. lpp.

2. Foo J. Y., Wilson S. J. (2006) Detection Method to Minimize Variability in Photoplethysmographic Signals for Timing-Related Measurement. Journal of Medical Engineering \&. Technology., 30 (2), p. 93-96.

3. Gerhard - Herman M., Gardin J. M., Jaff M, Mohler E., Roman M., Naqvi T., Z. (2006) Guidlines for Noninvasive Vascular Laboratory Testing: AReport from the American Society of Echocardiography and the Society of Vascular Medicine and Biology. Journal of the American Society of Echocardiography, 19 (8), p. 955-972.

4. Lasmane D. (2005) Stress „,bērna darbavietā” - skolā. Psihologijas pasaule (5), p. 46.-48.

5. Moore N. C. (2000) A Review of EEG Biofeedback Treatment of Anxiety Disorders. Clinical Electroencephalography, 31 (1), p. 1-6.

6. Ranka I., Miezīte S., Kalniņa I., Everika G. (1996) Skolēnu garīgā veselība Latvijā. Latvijas ārsts (2), $89-92$. 1pp.

7. Roge J. Mēlere B. (2003) Citādi bērni: Kā saprasties ar bērniem, kuri neietilpst valdošo priekšstatu rāmjos. Rīga: Jumava, 116 lpp.

8. Špalleka R. (2003) Palīdzība maziem haotiķiem. Rīga: Nordik, 207 lpp.

9. Yashima K., Sasaki T., Kageyama Y., Odagaki M., Hosaka H. (2005) Application of Wavelet Analysis to the Plethysmogram for the Evaluation of Mental Stress. Engineering in Medicine and Biology $27^{\text {th }}$ Annual International Conference, p. 2781-2784.

10. Zīriṇa T. (2005) Hiperaktīvo bērnu attīstības īpatnību raksturojums dažādos vecumposmos. Psihologijas pasaule (6), 3.-9. lpp.

Asoc. prof. Dr. biol. Juris Porozovs

Riga Teacher Training and Educational Management Academy

Address: Imantas 7. līnija - 1., Rīga, LV-1083, Latvija

Phone: +371 7808120, mob.+371 26806992, fakss +371 7808034

E-mail: juris.porozovs@rpiva.lv

Dr. med. Nelli Tolmača

Psychoneurophysiology and Bioregulation Research Centre

Address: Lāčplēša iela 106/108, Rīga, Latvia

Phone: +371 29225291

E-mail: tolmacha@zb.lv

Dr. med. Jānis Vandāns

Psychoneurophysiology and Bioregulation Research Centre

Address: Lāčplēša iela 106/108, Rīga, Latvia

Phone: +371 29453832

E-mail: nms.diagnostika@parks.lv 